RAD Conference Proceedings, vol. 3, pp. 231-235, 2018

ISSN 2466-4626 (online) | DOI: 10.21175/RadProc.2018.48

www.rad-proceedings.org

\title{
A QUANTUM CHEMICAL INVESTIGATION OF N¹-SUBSTITUTED 1,2,4-TRIAZOLE
}

\author{
Vesna Dimova1 ${ }^{*}$, Mirjana S. Jankulovska², Milena Jankulovska3
}

${ }^{1}$ Faculty of Technology and Metalurgy, Ss Cyril and Methodius University, Skopje, Macedonia

${ }^{2}$ Faculty of Agricultural Sciences and Food, Ss. Cyril and Methodius University, Skopje, Macedonia

3University St. Kliment Ohridski, Chemical-Bromatological-Toxicological Analysis Laboratory, Higher Medical School

in Bitola, Macedonia

\begin{abstract}
The molecular conformations and electronic properties of a set of five $N^{1-}(o / p$-substituted phenyl)aminomethyl-1,2,4-triazole derivatives (PhAMT) were investigated by two semiempirical methods: AM1 and $P M_{3}$. Characteristic bond lengths $\left(\mathrm{N}_{1}-\mathrm{C}_{2}, \mathrm{C}_{2}-\mathrm{H}_{6}, \mathrm{C}_{2}-\mathrm{N}_{3}, \mathrm{~N}_{3}-\mathrm{N}_{4}, \mathrm{~N}_{4}-\mathrm{C}_{5}, \mathrm{C}_{5}-\mathrm{H}_{7}\right.$ and $\left.\mathrm{N}_{1}-\mathrm{C}_{5}\right)$, angles $\left(\mathrm{N}_{1}-\mathrm{C}_{2}-\mathrm{N}_{3}, \mathrm{C}_{2}-\mathrm{N}_{3}-\mathrm{N}_{4}\right.$, $N_{3}-N_{4}-C_{5}, N_{4}-C_{5}-N_{1}$ and $\left.C_{5}-N_{1}-C_{2}\right)$ and atomic charges $\left(N_{1}, C_{2}, N_{3}, N_{4}, C_{5}, H_{6}\right.$ and $\left.H_{7}\right)$ for 1,2,4-triazole core were calculated and discussed in accordance with literature data for similar 1,2,4-triazole compounds. The Еномо and $E_{\mathrm{LU}}$ values, total energies, the heats of formation and dipole moments values were calculated, as well. The discussion was performed in accordance with the type and position of a substituent present in the aromatic core.
\end{abstract}

Key words: AM1, PM3, atomic charge, bond length, dipole moment, EHOMO, ELUMO, heat of formation, 1,2,4triazole derivatives

\section{INTRODUCTION}

Among different heterocyclic systems, 1,2,4triazoles belong to a significant class of heterocyclic compounds due to their diverse biological properties. [1]. Triazole compounds in their structure contain five member rings with three nitrogen atoms and they have different structural formulas. It is well known that the parent $1,2,4$-triazole ( $1 \mathrm{H}$ form) is in tautomeric equilibrium with the 1,2,4-triazole ( $4 \mathrm{H}$ form) [2].

According to the latest literature, five membered heterocycles such as 1,2, 4-triazole ring are significant units in drug design [3]. Triazoles form is an important cluster among the heterocyclic compounds which possess a wide range of biological applications. The 1,2,4-triazole derivatives possess important pharmacological activities such as antifungal and antiviral [4]. The examples of antifungal drugs are itraconazole, fluconazole, ravuconazole, voriconazole and posaconazole [5]. Furthermore, 1,2,4-triazole derivatives are reported as insecticides, antiasthmatics, anticonvulsants, antidepressants, anti-inflammatory, insecticidal and plant growth regulators [6].

This paper represents a semiempirical quantum chemical investigation of chosen $\mathrm{N}^{1}$-substituted-1,2,4triazole derivatives PhAMT (1-5) previously synthesized and investigated [7]. The molecular conformations and electronic properties of investigated molecules were studied by AM1 and PM3 semiempirical methods. The total energies, heats of formation, dipole moments, geometric parameters, ionization potential, full atomic charges, $E_{\text {Hомо }}$ and $E_{\text {LUMO values were calculated and discussed. }}$

\section{EXPERIMENTAL}

\subsection{Materials and methods}

$\mathrm{N}^{1}$-(o/p-substituted phenyl)aminomethyl-1,2,4triazole derivatives (PhAMT 1-5), (See Table 1), used in this study were previously synthesized and reported elsewhere [7].

\subsection{Quantum chemical investigation}

Theoretical calculations were performed by using HYPERCHEM program [8]. The geometries of $\mathrm{N}^{1-}$ (o/p-substituted phenyl)aminomethyl-1,2,4-triazole derivatives (PhAMT 1-5) were fully optimized using $\mathrm{AM} 1$ and $\mathrm{PM}_{3}$ semiempirical method. All the structures were optimized to a gradient norm of $<0.1$.

AM1 (Austin model 1) AM1 is a semiempirical method based on the neglect of differential diatomic overlap integral approximation. Specifically, it is a generalization of the modified neglect of diatomic differential overlap approximation. AM1 was developed by Michael Dewar and coworkers reported in 1985 [9].

$\mathrm{PM}_{3}$ (parameterized model number 3 ) $\mathrm{PM}_{3}$ is another semiempirical method based on the neglect of differential diatomic overlap integral approximation. The $\mathrm{PM}_{3}$ method uses the same formalism and equations such as the AM1 method. The only

*vdimova@tmf.ukim.edu.mk 
V. Dimova et al., A quantum chemical investigation..., RAD Conf. Proc., vol. 3, 2018, 231-235

differences are: (a) PM3 uses two Gaussian functions for the core repulsion function instead of the variable number used by AM1 (which uses between one and four Gaussians per element); (b) the numerical values of the parameters are different. The other differences lie in the philosophy and the methodology used during the parameterization: whereas AM1 takes some of the parameter values from spectroscopic measurements, $\mathrm{PM}_{3}$ treats them as optimized values. The PM3 method was developed by Stewart and first reported in 1989 [10].

Table 1. Structure of investigated N1-(o/p-substituted phenyl)aminomethyl-1,2,4-triazole derivatives (PhAMT 1 - PhAMT 5)

PhAMT 1
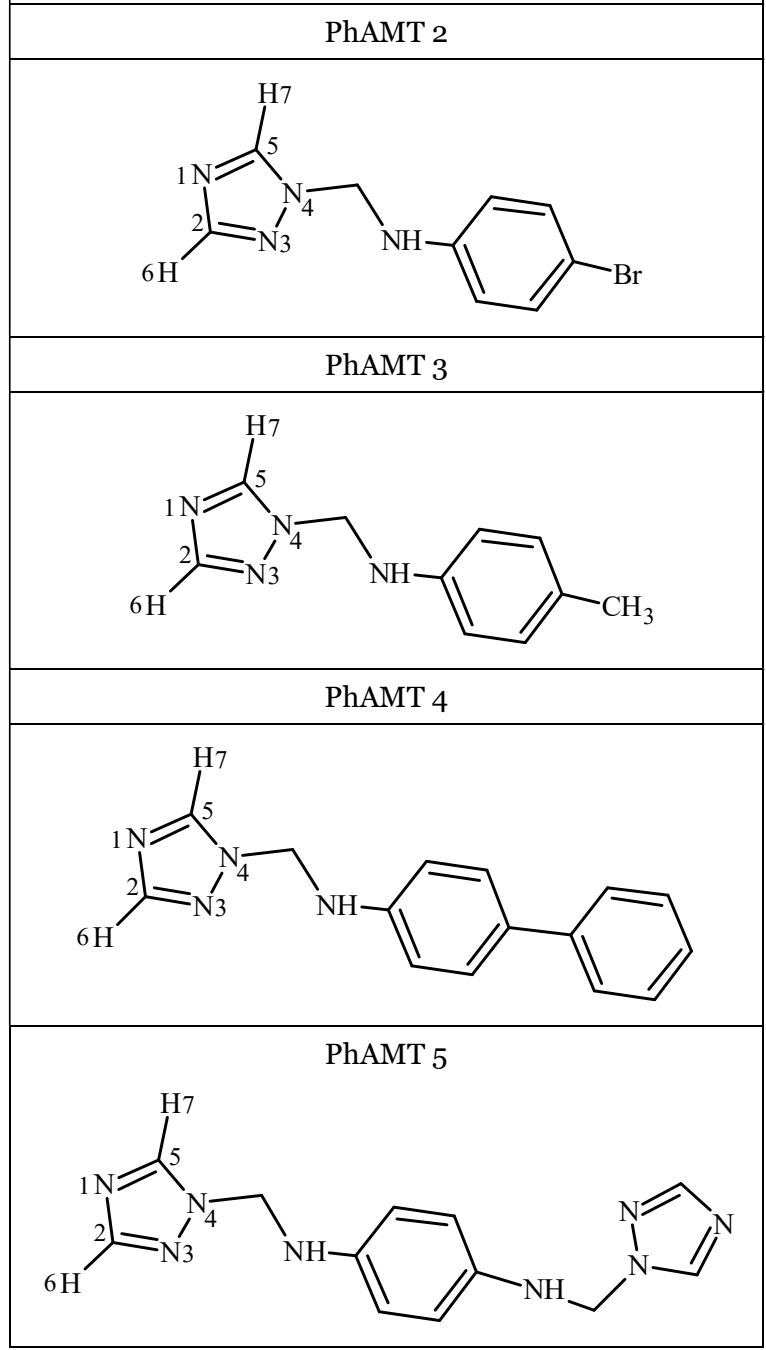

\section{RESULTS AND DISCUSSION}

The study of the geometry of complex system such as investigated ones (PhAMT 1-5) is important because of the possible usefulness of such information as an aid to the understanding of the mode of action of PhAMT:

$\bigcirc \quad$ as acid or as base and

O co-coordinative species

The optimized geometrical parameters of selected $\mathrm{N}^{1}$-(o/ $p$-substituted phenyl)aminomethyl-1,2,4-triazole derivatives (PhAMT 1-5) such as: bond length, angles and atomic charge are presented in Tables 2 and 3 .

Table 2. Selected geometrical parameters: bond length, angle and of atomic charge of PhAMT 1-5 calculated by AM1 semiempirical method

\begin{tabular}{|c|c|c|c|c|c|}
\hline AM1 & PhAMT 1 & PhAMT 2 & PhAMT 3 & PhAMT 4 & PhAMT 5 \\
\hline \multicolumn{6}{|c|}{ Length [Å] } \\
\hline $\mathrm{N}_{1}-\mathrm{C}_{2}$ & 1.4120 & 1.4114 & 1.4082 & 1.4107 & 1.4089 \\
\hline $\mathrm{C}_{2}-\mathrm{N}_{3}$ & 1.3593 & 1.3599 & 1.3623 & 1.3604 & 1.3620 \\
\hline $\mathrm{N}_{3}-\mathrm{N}_{4}$ & 1.3486 & 1.3481 & 1.3444 & 1.3475 & 1.3438 \\
\hline $\mathrm{N}_{4}-\mathrm{C}_{5}$ & 1.4168 & 1.4160 & 1.4122 & 1.4152 & 1.4142 \\
\hline $\mathrm{N}_{1}-\mathrm{C}_{5}$ & 1.3452 & 1.3458 & 1.3487 & 1.3405 & 1.3480 \\
\hline $\mathrm{C}_{2}-\mathrm{H}_{6}$ & 1.0945 & 1.0949 & 1.0942 & 1.0949 & 1.0944 \\
\hline $\mathrm{C}_{5}-\mathrm{H}_{7}$ & 1.0947 & 1.0948 & 1.0938 & 1.0947 & 1.0937 \\
\hline \multicolumn{6}{|c|}{ Angle [deg] } \\
\hline $\mathrm{N}_{1}-\mathrm{C}_{2}-\mathrm{N}_{3}$ & $112.99^{\circ}$ & $112.98^{\circ}$ & $112.88^{\circ}$ & $112.98^{\circ}$ & $112.92^{\circ}$ \\
\hline $\mathrm{C}_{2}-\mathrm{N}_{3}-\mathrm{N}_{4}$ & $104.62^{\circ}$ & $104.63^{\circ}$ & $104.78^{\circ}$ & $104.62^{\circ}$ & $104.83^{\circ}$ \\
\hline $\mathrm{N}_{3}-\mathrm{N}_{4}-\mathrm{C}_{5}$ & $109.57^{\circ}$ & $109.57^{\circ}$ & $109.53^{\circ}$ & $109.60^{\circ}$ & $109.45^{\circ}$ \\
\hline $\mathrm{N}_{4}-\mathrm{C}_{5}-\mathrm{N}_{1}$ & $109.18^{\circ}$ & $109.20^{\circ}$ & $109.35^{\circ}$ & $109.19^{\circ}$ & $109.4^{\circ}$ \\
\hline $\mathrm{C}_{5}-\mathrm{N}_{1}-\mathrm{C}_{2}$ & $103.58^{\circ}$ & $103.56^{\circ}$ & $103.43^{\circ}$ & $103.55^{\circ}$ & $103.38^{\circ}$ \\
\hline \multicolumn{6}{|c|}{ Atomic charge } \\
\hline $\mathrm{N}_{1}$ & -0.154 & -0.155 & -0.159 & -0.156 & -0.155 \\
\hline $\mathrm{C}_{2}$ & -0.151 & -0.149 & -0.157 & -0.152 & -0.163 \\
\hline $\mathrm{N}_{3}$ & -0.08 & -0.091 & -0.099 & -0.091 & -0.079 \\
\hline $\mathrm{N}_{4}$ & -0.187 & -0.184 & -0.199 & -0.182 & -0.199 \\
\hline $\mathrm{C}_{5}$ & -0.067 & -0.066 & -0.080 & -0.068 & -0.096 \\
\hline $\mathrm{H}_{6}$ & 0.212 & 0.212 & 0.208 & 0.211 & 0.208 \\
\hline $\mathrm{H}_{7}$ & 0.212 & 0.212 & 0.206 & 0.212 & 0.240 \\
\hline
\end{tabular}

Table 3. Selected geometrical parameters: length, angle and of atomic charge of PhAMT 1-5 calculated by PM3 semiempirical method

\begin{tabular}{|c|c|c|c|c|c|}
\hline PM3 & \multirow{2}{*}{ PhAMT 1 } & PhAMT 2 & PhAMT 3 & PhAMT 4 & PhAMT 5 \\
\hline \multicolumn{5}{|c|}{ Length [Å] } \\
\hline $\mathrm{N}_{1}-\mathrm{C}_{2}$ & 1.3927 & 1.3927 & 1.3923 & 1.3919 & 1.3932 \\
\hline $\mathrm{C}_{2}-\mathrm{N}_{3}$ & 1.3447 & 1.3447 & 1.3446 & 1.3453 & 1.3441 \\
\hline $\mathrm{N}_{3}-\mathrm{N}_{4}$ & 1.3755 & 1.3762 & 1.3756 & 1.3760 & 1.3747 \\
\hline $\mathrm{N}_{4}-\mathrm{C}_{5}$ & 1.3907 & 1.3904 & 1.3906 & 1.3896 & 1.3920 \\
\hline $\mathrm{N}_{1}-\mathrm{C}_{5}$ & 1.3477 & 1.3478 & 1.3474 & 1.3485 & 1.3466 \\
\hline $\mathrm{C}_{2}-\mathrm{H}_{6}$ & 1.0922 & 1.0921 & 1.0923 & 1.0922 & 1.0924 \\
\hline $\mathrm{C}_{5}-\mathrm{H}_{7}$ & 1.0934 & 1.0935 & 1.0934 & 1.0936 & 1.0933 \\
\hline \multicolumn{7}{|c|}{ Angle [deg] } \\
\hline $\mathrm{N}_{1}-\mathrm{C}_{2}-\mathrm{N}_{3}$ & $109.21^{\circ}$ & $109.21^{\circ}$ & $09.19^{\circ}$ & $109.22^{\circ}$ & $109.16^{\circ}$ \\
\hline $\mathrm{C}_{2}-\mathrm{N}_{3}-\mathrm{N}_{4}$ & $106.40^{\circ}$ & $106.39^{\circ}$ & $106.44^{\circ}$ & $106.37^{\circ}$ & $106.50^{\circ}$ \\
\hline $\mathrm{N}_{3}-\mathrm{N}_{4}-\mathrm{C}_{5}$ & $109.65^{\circ}$ & $109.65^{\circ}$ & $109.60^{\circ}$ & $109.67^{\circ}$ & $109.57^{\circ}$ \\
\hline $\mathrm{N}_{4}-\mathrm{C}_{5}-\mathrm{N}_{1}$ & $106.30^{\circ}$ & $106.29^{\circ}$ & $106.33^{\circ}$ & $106.30^{\circ}$ & $106.31^{\circ}$ \\
\hline $\mathrm{C}_{5}-\mathrm{N}_{1}-\mathrm{C}_{2}$ & $108.43^{\circ}$ & $108.44^{\circ}$ & $108.44^{\circ}$ & $108.42^{\circ}$ & $108.45^{\circ}$ \\
\hline \multicolumn{7}{|c|}{ Atomic charge } \\
\hline $\mathrm{N}_{1}$ & -0.169 & -0.171 & -0.169 & -0.174 & -0.165 \\
\hline $\mathrm{C}_{2}$ & -0.073 & -0.071 & -0.072 & -0.072 & -0.076 \\
\hline $\mathrm{N}_{3}$ & -0.239 & -0.244 & -0.239 & -0.247 & -0.227 \\
\hline $\mathrm{N}_{4}$ & -0.2167 & -0.219 & -0.179 & -0.222 & -0.181 \\
\hline $\mathrm{C}_{5}$ & -0.174 & -0.170 & -0.171 & -0.168 & -0.183 \\
\hline $\mathrm{H}_{6}$ & 0.162 & 0.162 & 0.162 & 0.161 & 0.163 \\
\hline $\mathrm{H}_{7}$ & 0.167 & 0.169 & 0.169 & 0.170 & 0.169 \\
\hline
\end{tabular}


V. Dimova et al., A quantum chemical investigation..., RAD Conf. Proc., vol. 3, 2018, 231-235

3.1. Characteristic bond length in 1,2,4-triazole ring

Bond length characteristic for 1,2,4-triazole moiety in PhAMT (1-5) molecule are: $\mathrm{N}_{1}-\mathrm{C}_{2}, \mathrm{C}_{2}-\mathrm{H}_{6}, \mathrm{C}_{2}-\mathrm{N}_{3}, \mathrm{~N}_{3}-$ $\mathrm{N}_{4}, \mathrm{~N}_{4}-\mathrm{C}_{5}, \mathrm{C}_{5}-\mathrm{H}_{7}$ and $\mathrm{N}_{1}-\mathrm{C}_{5}$. The obtained data are presented in Tables 2 and 3.

Calculated bond lengths values are comparable with the corresponding experimental ones for unsubstituted $1 \mathrm{H}-1,2,4$-triazole [11].

It can be noticed (See Tables 2 and 3 ) that the bond lengths of the $\mathrm{N}-\mathrm{N}$ bond in 1,2,4-triazole core calculated with: i) AM1 method range from $1.3438 \div$ 1.3486 A; ii) PM3 method range from $1.3747 \div 1.3762$ $\AA$, which is shorter compared with the normal N-N

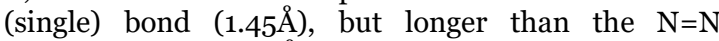
(double) bond $(1.25 \AA)$ [12]. The values calculated by AM1 are in good agreement with the same distance in 1,2,4-triazole (1.350) according to the literature [13].

The C-N bonds in PhAMT (1-5) can be classified according to the bond type observed: $\mathrm{N}_{1}-\mathrm{C}_{2} / \mathrm{N}_{4}-\mathrm{C}_{5}$ and $\mathrm{C}_{2}-\mathrm{N}_{3} / \mathrm{N}_{1}-\mathrm{C}_{5}$.

The single $\mathrm{C}-\mathrm{N}$ covalent bond ( $\left.\mathrm{N}_{1}-\mathrm{C}_{2} / \mathrm{N}_{4}-\mathrm{C}_{5}\right)$ can be compared with the corresponding values reported in literature [11] for unsubstituted $1 \mathrm{H}-1,2,4^{-}$ triazole:

i) for PhAMT (1-5)

○ $\mathrm{N} 1$ - $\mathrm{C} 2: 1.4083 \div 1.4120 \AA$ (AM1) and $1.3919 \div$ $1.3932 \AA\left(\mathrm{PM}_{3}\right)$;

○ $\mathrm{N}_{4}-\mathrm{C}_{5}: 1.4122 \div 1.4168 \AA$ (AM1) and $1.3896 \div$ $1.3920 \AA$ ( $\left.\mathrm{PM}_{3}\right)$.

ii) Literature values for the same distance in $1 \mathrm{H}$ 1,2,4-triazole [11]:

$\circ$ experimental values: $1.348 \AA\left(\mathrm{N}_{1}-\mathrm{C} 2\right)$ and $1.377 \AA$ ( $\mathrm{N}_{4}-\mathrm{C}_{5}$ );

○ calculated with $\mathrm{PM}_{3}$ method: $1.386 \AA$ (N1 - C2) and $1.383 \AA$ ( $\left.\mathrm{N}_{4}-\mathrm{C}_{5}\right)$

iii) typical single $C-N$ bond: $1.47 \AA$ [12]

Second type $\mathrm{C}=\mathrm{N}$ (double) covalent bond in triazole ring has following values:

i) for PhAMT (1-5)

○ C2-N3: $1.3593 \div 1.3623 \AA$ (AM1) and $1.3441 \div$ $1.3453 \AA$ ( $\left.\mathrm{PM}_{3}\right)$;

○ $\quad \mathrm{N}_{1}-\mathrm{C}_{5}: 1.3405 \div 1.3487 \AA$ (AM1) and 1.3466 $\div 1.3485 \AA\left(\mathrm{PM}_{3}\right)$.

ii) Literature values for $1 \mathrm{H}-1,2,4$-triazole [11]:

$\circ \mathrm{C}_{2}-\mathrm{N}_{3}: 1.305 \AA$ (exp.), $1.351 \AA$ (calc.) and

○ N1-C5: $1.329 \AA$ (exp.), $1.353 \AA$ (calc.)

iii) typical single $\mathrm{C}=\mathrm{N}$ bond: $1.287 \AA$ [12]

\subsection{Characteristic angles in 1,2,4-triazole ring}

The optimized geometrical structures of PhAMT (15) showed corresponding angle values (Tables 2 and 3):

O $\mathrm{N}_{1}-\mathrm{C}_{2}-\mathrm{N}_{3}: 112.88 \div 112.99^{\circ}$ calculated by $\mathrm{AM} 1$ method; $109.16 \div 109.22^{\circ}$ calculated by $\mathrm{PM}_{3}$ method;

○ $\mathrm{C}_{2}-\mathrm{N}_{3}-\mathrm{N}_{4}: 104.62 \div 104.83^{\circ}$ calculated by AM1 method;

Total energies $\left(E_{\mathrm{tot}}\right)$, the heats of formation $\left(\Delta H_{f}{ }^{o}\right)$, energies of frontier molecular orbitals: the highest occupied ( $\left.E_{\text {номо }}\right)$ and the lowest unoccupied molecular orbital ( $E_{\text {LUMo }}$ ) and dipole moments $\mu$ (in Debyes) of PhAMT (1-5) were calculated. The obtasined values are given in Table 4. In fact, the stability of complex heterocyclic systems such as PhAMT (1-5), depends on the conjugation between the: heterocyclic ring, (in this case 1,2,4-triazole), aminomethyl unit and $o / \mathrm{p}-$ substituted aromatic rings.

- $106.37 \div 160.50^{\circ}$ calculated by $\mathrm{PM}_{3}$ method;

- $\mathrm{N}_{3}-\mathrm{N}_{4}-\mathrm{C}_{5}: 109.45 \div 109.60^{\circ}$ calculated by $\mathrm{AM} 1$ method; $109.57 \div 109.67^{\circ}$ calculated by $\mathrm{PM}_{3}$ method;

○ $\quad \mathrm{N}_{4}-\mathrm{C}_{5}-\mathrm{N}_{1}: 109.18 \div 109.40^{\circ}$ calculated by AM1 method; $106.29 \div 106.33^{\circ}$ calculated by $\mathrm{PM}_{3}$ method;

○ $\mathrm{C}_{5}-\mathrm{N}_{1}-\mathrm{C}_{2}: 103.38 \div 103.58^{\circ}$ calculated by $\mathrm{AM} 1$ method; $108.42 \div 108.45^{\circ}$ calculated by $\mathrm{PM}_{3}$ method.

According to the literature [11], corresponding angle values calculated for unsubstituted triazole ring are similar for $\mathrm{N}=\mathrm{C}-\mathrm{N}\left(113.80^{\circ}\right)$ in case when both $\mathrm{N}$ atom have no $\mathrm{H}$ atom. The angle values for $\mathrm{C}-\mathrm{N}-\mathrm{N}$ were $102.70^{\circ}$ when central $\mathrm{N}$ atom has no $\mathrm{H}$ atom and $105.70^{\circ}$ for $\mathrm{C}-\mathrm{N}-\mathrm{C}$ angle.

\subsection{Characteristic atomic charges in 1,2,4-triazole ring}

It is known that atomic charges in the molecule are obviously responsible for electrostatic interactions. Thus, they are often used for the description of the molecular polarity of molecules. Mulliken population analysis is generally used for the calculation of the charge distribution in different molecules because these numerical quantities are easy to calculate. Furthermore, they provide a qualitative understanding not only of the structure but also the reactivity of the molecules.

Table 4. Total energies, heats of formation, semiempirical calculated relative stabilities, $E_{\text {HOMO }}$ and $E_{\text {LuMO }}$ energies of frontier molecular orbitals, dipol moments for PhAMT (1-5)

\begin{tabular}{|c|c|c|c|c|c|}
\hline & PhAMT 1 & PhAMT 2 & PhAMT 3 & PhAMT 4 & PhAMT 5 \\
\hline & \multicolumn{5}{|c|}{ AM1 } \\
\hline $\begin{array}{c}\mu \\
{[D]}\end{array}$ & 3.237 & 0.873 & 2.354 & 3.112 & 0.824 \\
\hline $\begin{array}{c}E_{\text {HOMO }} \\
{[\mathrm{eV}]}\end{array}$ & -9.052 & -8.912 & -8.870 & -8.545 & -8.455 \\
\hline $\begin{array}{c}E_{\text {LUMo }} \\
\text { [eV] }\end{array}$ & -0.441 & -0.138 & 0.132 & -0.193 & 0.084 \\
\hline $\begin{array}{c}E_{\text {tot }} \\
{[\mathrm{kcal} / \mathrm{mol}]}\end{array}$ & -66.510 & -56.597 & -52.364 & -67.742 & -77.927 \\
\hline \multirow[t]{2}{*}{$\begin{array}{c}\Delta H_{f} \\
{[\mathrm{kcal} / \mathrm{mol}]}\end{array}$} & 29.767 & 123.895 & 107.249 & 144.635 & 210.886 \\
\hline & \multicolumn{5}{|c|}{ PM3 } \\
\hline $\begin{array}{c}\mu \\
{[\mathrm{D}]}\end{array}$ & 4.101 & 2.993 & 2.550 & 3.960 & 0.157 \\
\hline $\begin{array}{c}E_{\text {Hомо }} \\
\text { [eV] }\end{array}$ & -9.255 & -9.186 & -8.894 & -8.857 & -8.643 \\
\hline $\begin{array}{c}E_{\text {LUMO }} \\
{[\mathrm{eV}]}\end{array}$ & -0.748 & -0.302 & -0.057 & -0.399 & -0.183 \\
\hline $\begin{array}{c}\boldsymbol{E}_{\mathrm{tot}} \\
{[\mathrm{kcal} / \mathrm{mol}]}\end{array}$ & -59.356 & -50.864 & -46.522 & -60.874 & -67.623 \\
\hline $\begin{array}{c}\Delta H_{f} \\
{[\mathrm{kcal} / \mathrm{mol}]}\end{array}$ & 62.433 & 89.490 & 71.416 & 106.049 & 139.910 \\
\hline
\end{tabular}

The Mulliken atomic charge of the 1,2,4-triazole core atoms calculated by AM1 and PM3 methods are listed in Tables 2 and 3 . The results pointed that:

O AM1: $\mathrm{N}_{4}$ atom and 
O PM3: $\mathrm{N}_{3}$ atom

in all investigated triazoles were atoms with the highest negative values. In accordance with the negative charge distribution on atoms in the PhAMT (1-5), the $\mathrm{N}_{4} / \mathrm{N}_{3}$ was predicted to be the main site of the molecule for the electrophilic attack of hydrogen. Since, both investigated hydrogen atoms ( $\mathrm{H} 6$ and $\mathrm{H} 7$ ) had similar atomic charge values, they had the same possibility of carrying out the deprotonation process in both cases: $\mathrm{C}_{2}-\mathrm{H} 6$ and $\mathrm{C}_{5}-\mathrm{H}_{7}$.

Total energies $\left(E_{\mathrm{tot}}\right)$, the heats of formation $\left(\Delta H_{f}{ }^{\rho}\right)$, energies of frontier molecular orbitals: the highest occupied ( $E_{\text {НОмо }}$ ) and the lowest unoccupied molecular orbital ( $\left.E_{\mathrm{Lumo}}\right)$ and dipole moments $\mu$ (in Debyes) of PhAMT (1-5) were calculated (See Table 4). In fact, the stability of complex heterocyclic systems, such as PhAMT (1-5) depends on the conjugation between the heterocyclic ring, (in this case 1,2,4-triazole), aminomethyl unit and $o / p$ - substituted aromatic rings.

\subsection{Dipole moment $(\mu)$}

The dipole moment of the molecule is the most widely used quantity to describe their polarity. The size of the dipole moment calculated by both semiempirical methods (AM1 and $\mathrm{PM}_{3}$ ) depends on the type and position $(o-/ p-)$ of substituent associated with the aminomethyl-phenyl unit. PhAMT 1 , with $o$ substituted $-\mathrm{COOH}$ group relative to the benzene core had the highest dipole moment: 3.237 D (AM1) and 4.101 D (PM3). The lowest dipole moment had PhAMT 5 in which the second triazole nucleus is divided from benzene core by an additional aminomethyl bridge: o.824 D (AM1) and 0.157 D (PM3) (Table 4).

\subsection{Total energies $\left(E_{\text {tot }}\right)$}

Knowing that the total energy of a system is composed of internal, potential and kinetic energy, the total energy calculated by quantum chemical methods (AM1 and PM3) is also an important parameter for the understanding of the structure and reactivity of the investigated triazole molecules. PhAMT 5 had the highest negative values for total energies calculated by AM1 and PM3 method (Table 4). Triazole with $p$ substituted moderately activating group such as $-\mathrm{CH}_{3}$ (PhAMT 3) had the lowest negative total energies values (Table 4).

\subsection{Molecular orbital energies}

The frontier orbital: $E_{\text {номо and }} E_{\text {Lumo }}$ (highest/lowest occupied molecular orbital energy) are very known quantum chemical parameters. They determine the way the molecule interacts with other species in chemical reactions and play important role in the optical and electrical properties [12]. According to the frontier molecular orbital theory, the highest occupied molecular orbital is the orbital that could act as an electron donor, while the lowest occupied molecular orbital could act as the electron acceptor. The formation of a transition state is due to an interaction between the frontiers orbital of reactants.

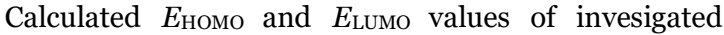
triazoles are presented in Table 4. The HOMO-LUMO gap $\left(E_{\text {gap }}=E_{\text {Hомо }}-E_{\text {LUMO }}\right)$ is an important stability 234 indicator. The larger values of $E_{\text {gap }}$ imply high stability of the molecule in chemical reactions [14], and the smaller values indicate that the molecule is more probable to give higher inhibition efficiency.

The $E_{\mathrm{HOMO}}$ is directly related to the ionization potential (IP $\left.=-E_{\mathrm{HOMO}}\right)$ and the energy of the LUMO is directly related to the electron affinity. IP of PhAMT 1 had the higher values compared with the rest of compounds: 9.0520 calculated by AM1 method and 9.2553 calculated by $\mathrm{PM}_{3}$ method. Those values were lower than those reported in the literature for 1,2,4triazole. According to the literature, the experimental IP value of 1,2,4-triazole molecule was $10.00 \mathrm{eV}$, while calculated IP value using $\mathrm{AM}_{1}$ and $\mathrm{PM}_{3}$ methods was 10.27 and $10.396 \mathrm{eV}$, respectively [15].

\subsection{Heats of formation $\left(\Delta H_{f}{ }^{o}\right)$.}

Heat of formation (HOF) is one of the most crucial thermodynamic quantities. It is required to estimate the amount of energy released or absorbed in a chemical reaction in order to calculate other thermodynamic functions and, what is more important, to assess the stability of a molecule [16]. The heats of formations $\left(\Delta H_{f}{ }^{\circ}\right)$ for selected triazole compounds were also calculated using AM1 and PM3 semiempirical methods (Table 4). It can be clearly seen from the Table 4 that the $\Delta H_{f}{ }^{\circ}$ increased according to the following order in both cases:

PhAMT $5>$ PhAMT $4>$ PhAMT $2>$ PhAMT $3>$ PhAMT 1.

\section{CONCLUSION}

In the most cases, quantum chemical investigations can be used in structure elucidation of organic molecules and this kind of calculation should be performed as a prediction of possible synthesis and stability of the predictive product. The subject of this investigation was a set of five $\mathrm{N}^{1}-(\mathrm{o} / p$-substituted phenyl)aminomethyl-1,2,4-triazole derivatives PhAMT (1-5). Characteristic bond lengths, angles and atomic charges were calculated by AM1 and PM3 methods and compared with literature data for compounds with same heterocyclic core. All compared data were in a good agreement with each other. $E_{\text {HOMO }}$ and $E_{\text {LUMO }}$ values, total energies $\left(E_{\mathrm{tot}}\right)$, the heats of formation $\left(\Delta H_{f}^{\circ}\right)$, and dipole moments $(\mu)$ for investigated PhAMT (1-5) were also calculated and disscused in accordance with the structure of substituted triazoles. All the calculated data were useful not only for the characterization of the triazole molecules, but they also could help in understanding the type of action of PhAMT (1-5) especially in acid/base reactions and in coordinative chemistry. This information also could be helpful for fundamental researches in heterocyclic chemistry and biology, and also for further application of investigated compounds in pharmacy and other industries, as well. 


\section{REFERENCES}

1. S. Maddila et al., "1,2,4-Triazoles: A Review of Synthetic Approaches and the Biological Activity," Lett. Organic Chem., vol. 10, no. 10, pp. 693- 714, 2013. DOI: $10.2174 / 157017861010131126115448$

2. K. Ali et al., "Short review on 1, 2, 4-Triazole with various pharmacological activity," SD Int. J. Pharm. Sci., vol. 1, no. 1, pp. $14-22$, Jan. 2018. Retrieved from: http://www.sdijps.com/rc images/sdij ps1_1 14_22pdf.pdf; Retrieved on: Jul. 23, 2018

3. R. Singh et al., "Design and Synthesis of New Bioactive 1,2,4-Triazoles, Potential Antitubercular and Antimicrobial Agents," Indian J. Pharm. Sci., vol. 8o, no. 1, pp. $36-45,2018$. DOI: $10.4172 /$ pharmaceutical-sciences.1000328

4. N. Jaiprakash et al., "Synthesis, Antifungal Activity, and Docking Study of Some New 1,2,4-triazole Analogs," Chem. Biol. Drug Design, vol. 78, no. 5, pp. 800 - 809, Nov. 2011. DOI: $10.1111 / j .1747-0285.2011 .01178 . x$

5. H. Sadeghpour et al., "Design, Synthesis, and Biological Activity of New Triazole and Nitro-Triazole Derivatives as Antifungal Agents," Molecules, vol. 22, no. 7, 1150, Jul. 2017. DOI: org/10.3390/molecules22071150

6. A. Usman Rasheed et al., "ADME/T Prediction, Molecular Docking, and Biological Screening of 1,2,4Triazoles as Potential Antifungal Agents," J. Appl. Bioinform. Computat. Biol., vol. 7, no. 1, Jan. 2018. DOI: $10.4172 / 2329-9533.1000144$

7. M. Lazarevi et al., "Synthesis of some N 1 Aryl/heteroarylaminomethyl/ethyl-1,2,4-triazoles and their antibacterial and antifungal activities," Heterocycl. Commun., vol. 7, no. 1, pp. $577-582$, May 2001.

DOI: org/10.1515/HC.2001.7.6.577

8. HyperChem(TM) Professional 7.51, Hypercube, Inc., Gainesville (FL), USA, 2018.

Retrieved from: http://www.hyper.com/; Retrieved on: Jul. 23, 2018

9. M. J. S. Dewar et al., "Development and use of quantum mechanical molecular models. 76. AM1: a new general purpose quantum mechanical molecular model," J. Am. Chem. Soc., vol. 107, no. 13, pp. 3902 - 3909, Jun, 1985

DOI: $10.1021 /$ jaoo299a024

10. J. J.P. Stewart, "Optimization of parameters for semiempirical methods I. Method," J. Computat. Chem., vol. 10, no. 2, pp. 209 - 220, Mar. 1989. DOI: org/10.1002/jcc.540100208

11. R. D. Johnson III, NIST Computational Chemistry Comparison and Benchmark Database: NIST Standard Reference Database Number 101, Release 19, National Institute of Standard and Technology, Gaithersburg (MD), USA, 2018.

Retrieved from: http://cccbdb.nist.gov/

Retrieved on: Dec. 12, 2017

12. L. Xiao-Hong et al., "Quantum chemical studies on the structure and performance properties of 2,5,2'-triazido1,1'-azo-1,3,4-triazole," Indian J. Chem. Sec. A, vol. 53A, no. 3 , pp. $281-287$, Mar. 2014

Retrieved from: http://nopr.niscair.res.in/handle/1234 56789/27394; Retrieved on: Apr. 23, 2018

13. J. L. Escobar-Valderrama et al., "Crystal, molecular and electronic structure of 1- $H$-3-methyl-4-amine-5-thione1,2,4-triazol," Can. J. Chem., vol. 67, no. 2, pp. 198 - 201, Feb. 1989 . DOI: org/10.1139/v89-033

14. I. A. Adejoro et al, "Quantum Descriptors and Corrosion Inhibition Potentials of Amodaquine and Nivaquine," Chem. Sci. J., vol. 8, no. 1, 149, Jan. 2017. DOI: $10.4172 / 2150-3494.1000149$

15. A. A. Ikizler et al., "A Quantum-Chemical Investigation on 5,5'-BI(1H-1.2,4-Triazole))," Turk. J. of Chem., vol. 21, no. 4, pp. $353-362,1997$.

Retrieved from: http://journals.tubitak.gov.tr/chem/iss ues/kim-97-21-4/kim-21-4-16-97056.pdf; Retrieved on: Apr. 23, 2018

16. Z. Rui-Zhou et al., "Theoretical studies on a series of 1,2,4-triazoles derivatives as potential high energy density compounds", J. Chem. Sci., vol. 124, no. 5, pp. 995 - 1006, Sep. 2012.

DOI: $10.1007 / \mathrm{s} 12039-012-0304-7$ 